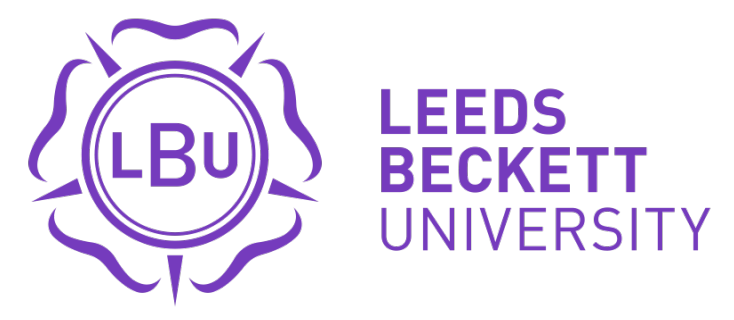

Citation:

Parker, JM and Glew, DW and Fletcher, M and Thomas, F and Gorse, C (2016) Accounting for refrigeration heat exchange in energy performance simulations of large food retail buildings. Building Services Engineering Research and Technology: an international journal. ISSN 1477-0849 DOI: https://doi.org/10.1177/0143624416675389

Link to Leeds Beckett Repository record:

https://eprints.leedsbeckett.ac.uk/id/eprint/3225/

Document Version:

Article (Accepted Version)

The aim of the Leeds Beckett Repository is to provide open access to our research, as required by funder policies and permitted by publishers and copyright law.

The Leeds Beckett repository holds a wide range of publications, each of which has been checked for copyright and the relevant embargo period has been applied by the Research Services team.

We operate on a standard take-down policy. If you are the author or publisher of an output and you would like it removed from the repository, please contact us and we will investigate on a case-by-case basis.

Each thesis in the repository has been cleared where necessary by the author for third party copyright. If you would like a thesis to be removed from the repository or believe there is an issue with copyright, please contact us on openaccess@leedsbeckett.ac.uk and we will investigate on a case-by-case basis. 


\title{
Accounting for refrigeration heat exchange in energy performance simulations of large food retail buildings
}

\author{
James Parker ${ }^{1}$, Martin Fletcher ${ }^{1}$, Felix Thomas ${ }^{1}$, David Glew ${ }^{1}$ and Christopher Gorse ${ }^{1}$ \\ ${ }^{1}$ Leeds Beckett University
}

\begin{abstract}
Heat exchange between chilled food storage and conditioned spaces in large food retail stores is not currently required as part of design stage regulatory compliance energy performance models. Existing work has identified that this exchange has a significant impact on store energy demand and subsequently leads to unrealistic assessment of building performance. Research presented in this paper uses whole building dynamic thermal simulation models that are calibrated against real store performance data, quantifying the impact of the refrigeration driven heat exchange. Proxy refrigerated units are used to simulate the impact of these units for the sales floor areas. A methodology is presented that allows these models to be simplified with the aim of calculating a realistic process heat exchange for refrigeration and including this in thermal simulation models; a protocol for the measurement of chilled sales areas and their inclusion in the building models is also proposed. It is intended that this modelling approach and the calculated process heat exchange inputs can be used to improve the dynamic thermal simulation of large food retail stores, reduce gaps between predicted and actual performance and provide more representative inputs for design stage and regulatory compliance energy calculations.
\end{abstract}

\section{Practical application}

The modelling methodology and research findings presented in the paper are of practical use for building energy modelling engineers using dynamic simulation models to design and/or evaluate the energy performance of large food retail stores. The methodology can be used in the design of new facilities or the evaluation of large scale retrofit projects. It is also of practical interest to energy and facility managers within large food retail organisations as it will aid their understanding of applied energy performance models.

\section{Key words}

Heat exchange, refrigeration, supermarkets, food retail, thermal modelling

\section{Introduction}

Large food retail stores (commonly known as supermarkets) are energy intensive, in the UK they account for approximately $3 \%$ of electricity demand and are responsible for $1 \%$ of greenhouse gas emissions. ${ }^{1}$ Energy used to refrigerate food in the sales floor area (SFA) and back of house $(\mathrm{BOH})$ storage can account for over $40 \%$ of a typical store's total consumption. ${ }^{2}$ Internal heat gains from refrigeration are nominally accounted for in regulatory compliance energy models but the data inputs currently used to represent these are unrealistic as will be demonstrated in this paper.

Published work by Hill et $a l^{2}$ quantifies the difference between energy consumption predicted by regulatory compliance models and a refined approach that includes the 'process gains' associated with SFA refrigeration. Inputs for chilled sales areas in 
regulatory compliance models are taken from the National Calculation Method (NCM) and are set at $25 \mathrm{~W} / \mathrm{m}^{2}$ for the $\mathrm{SFA}^{3}$. Although there is some heat gain from equipment in the SFA, the majority of refrigeration units in modern supermarkets use remote plant which rejects heat externally; this means that SFA refrigeration actually adds to the heating load rather than reducing it, as in the NCM approach. In the example model used by Hill et al, ${ }^{2}$ the SFA refrigeration accounts for $43 \%$ of the total heating load for the SFA. ${ }^{2}$

The research presented in this paper aims to quantify the refrigeration process heat exchange (PHE) associated with SFA refrigeration in order to produce a dynamic thermal simulation model input that can be used to more accurately predict the energy performance of large food retail buildings. This is achieved by methodically simplifying two calibrated dynamic thermal simulation (DTS) models as described in the main body of this paper.

\section{Energy consumption in large food retail stores}

The Chartered Institute of Building Services Engineers (CIBSE) publish energy performance benchmarks for non-domestic buildings that are used in the calculation of Display Energy Certificates (DEC) and represent a median value. ${ }^{4}$ Typical per annum benchmarks of $400 \mathrm{kWh} / \mathrm{m}^{2}$ for electricity and $105 \mathrm{kWh} / \mathrm{m}^{2}$ for fossil-thermal energy consumption are used for supermarkets. Within published academic literature, a range of normalised (per $\mathrm{m}^{2}$ ) values are cited based upon the SFA. Stores are categorised into the groups presented in Table 1; the SFA of a store is generally considered to account for approximately half of the total floor area. ${ }^{5,6}$

Table 1. Classification of retail food outlets. ${ }^{7}$

\begin{tabular}{ll}
\hline Store type: & Sales floor area $($ SFA $)$ \\
\hline Hypermarkets & $>5,750 \mathrm{~m}^{2}$ \\
Superstores & $1400 \mathrm{~m}^{2}-5750 \mathrm{~m}^{2}$ \\
Supermarkets & $280 \mathrm{~m}^{2}-1400 \mathrm{~m}^{2}$ \\
Convenience stores & $<280 \mathrm{~m}^{2}$ \\
\hline
\end{tabular}

There is a limited range of published data for single stores. A study based upon a supermarket $\left(1,266 \mathrm{~m}^{2} \mathrm{SFA}\right)$ records electricity consumption of $460 \mathrm{kWh} / \mathrm{m}^{2}$ per annum (pa) but does not report fossil-thermal consumption. ${ }^{8}$ A similar study of a larger store $\left(10,950 \mathrm{~m}^{2}\right)$, based in Scotland, modelled gas consumption of $83.1 \mathrm{kWh} / \mathrm{m}^{2}$ pa and electricity consumption of $414.3 \mathrm{kWh} / \mathrm{m}^{2} \mathrm{pa}^{2} .9$ Two larger scale studies of UK retail food outlet stores have been published. Tassou, Ge et $a l^{1}$ analysed consumption data from 2,570 facilities. They found that electrical energy intensity reduced proportionately as the size of the stores increased. Average intensities were found to be: $1,000 \mathrm{kWh} / \mathrm{m}^{2}$ for supermarkets; $920 \mathrm{kWh} / \mathrm{m}^{2}$ for superstores; and $770 \mathrm{kWh} / \mathrm{m}^{2}$ for hypermarkets. A wide variability in performance was identified across the large sample. ${ }^{1}$ The same piece of work states that the energy intensity of a store is dependent on the product mix, with smaller stores being more energy intensive due to proportionally higher densities of refrigerated and heated goods; there is consensus within industry supporting this notion. ${ }^{1,9,10}$ 
The number of SFA refrigeration units is dictated by store requirements and the number of units does not necessarily increase with store size. Figure 1 illustrates this relationship using data from a sample set of forty UK supermarkets which form the basis for this paper and a wider research project. When the size of the SFA increases, the ratio between Chilled SFA and Non-Chilled SFA also increases. This means that there is proportionately less floor area devoted to chilled SFAs in the larger stores.

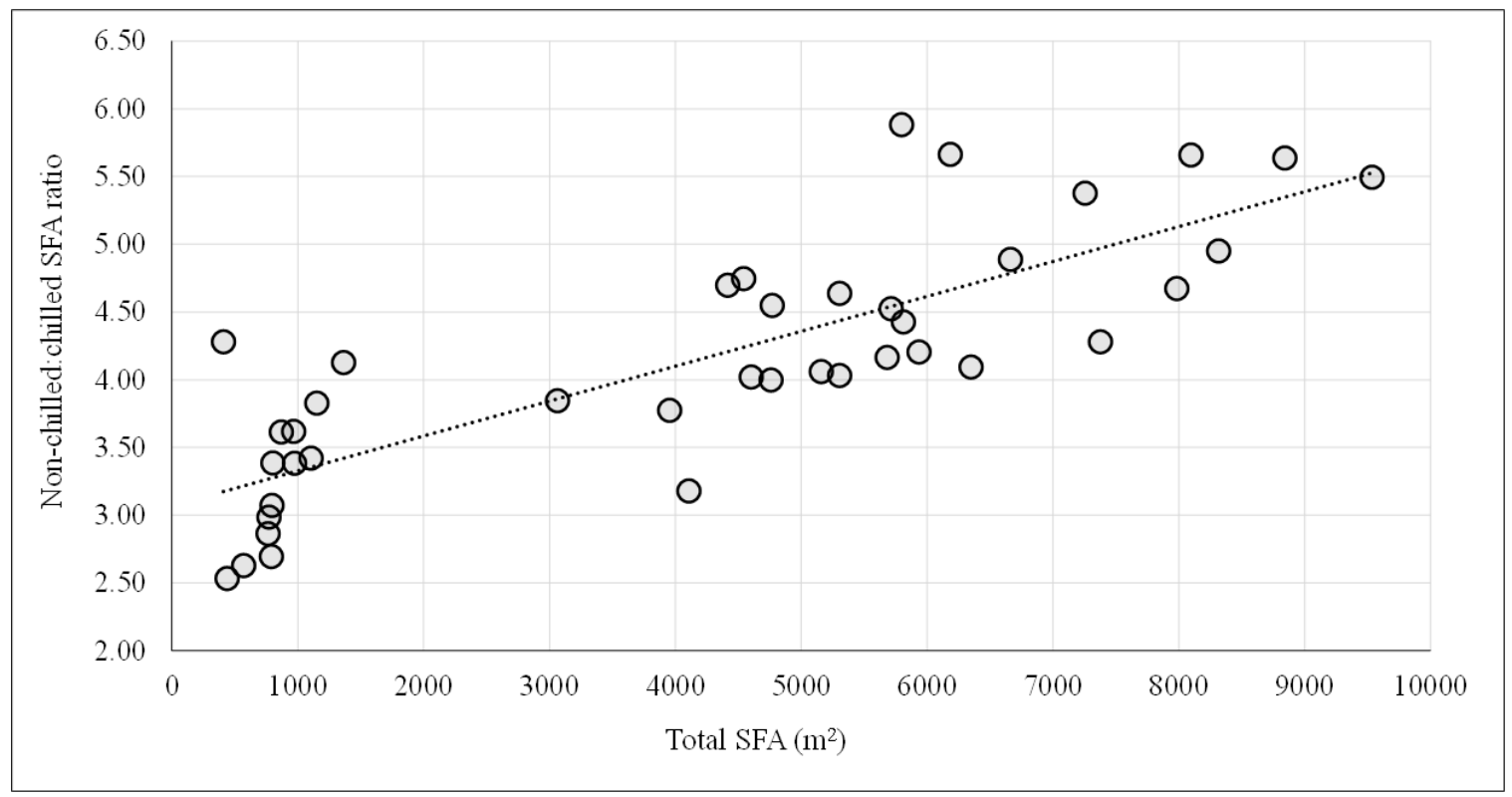

Figure 1. Relationship between total SFA and non-chilled:chilled SFA ratio across a sample set of forty large food retail stores.

Another large study of UK stores analysed data from a portfolio of hypermarkets. It found that average annual energy consumption was split between $79 \%$ for electricity and $21 \%$ for gas, equivalent to approximately $632 \mathrm{kWh} / \mathrm{m}^{2}$ and $168 \mathrm{kWh} / \mathrm{m}^{2}$ respectively. ${ }^{10}$ In the USA, a national average electrical energy intensity of $565 \mathrm{kWh} / \mathrm{m}^{2}$ pa was recorded and average annual energy consumption for a chain of supermarkets in Sweden was calculated as 421 $\mathrm{kWh} / \mathrm{m}^{2} .^{11}$ A comparison of the proportional end-use energy consumption reported in the literature is illustrated in Figure 2. It should be noted that the first three examples are for hypermarket variants (although, unlike the other examples, Jenkins' example is modelled for a single store) and the remaining example is for a range of stores in Sweden. ${ }^{11}$ 


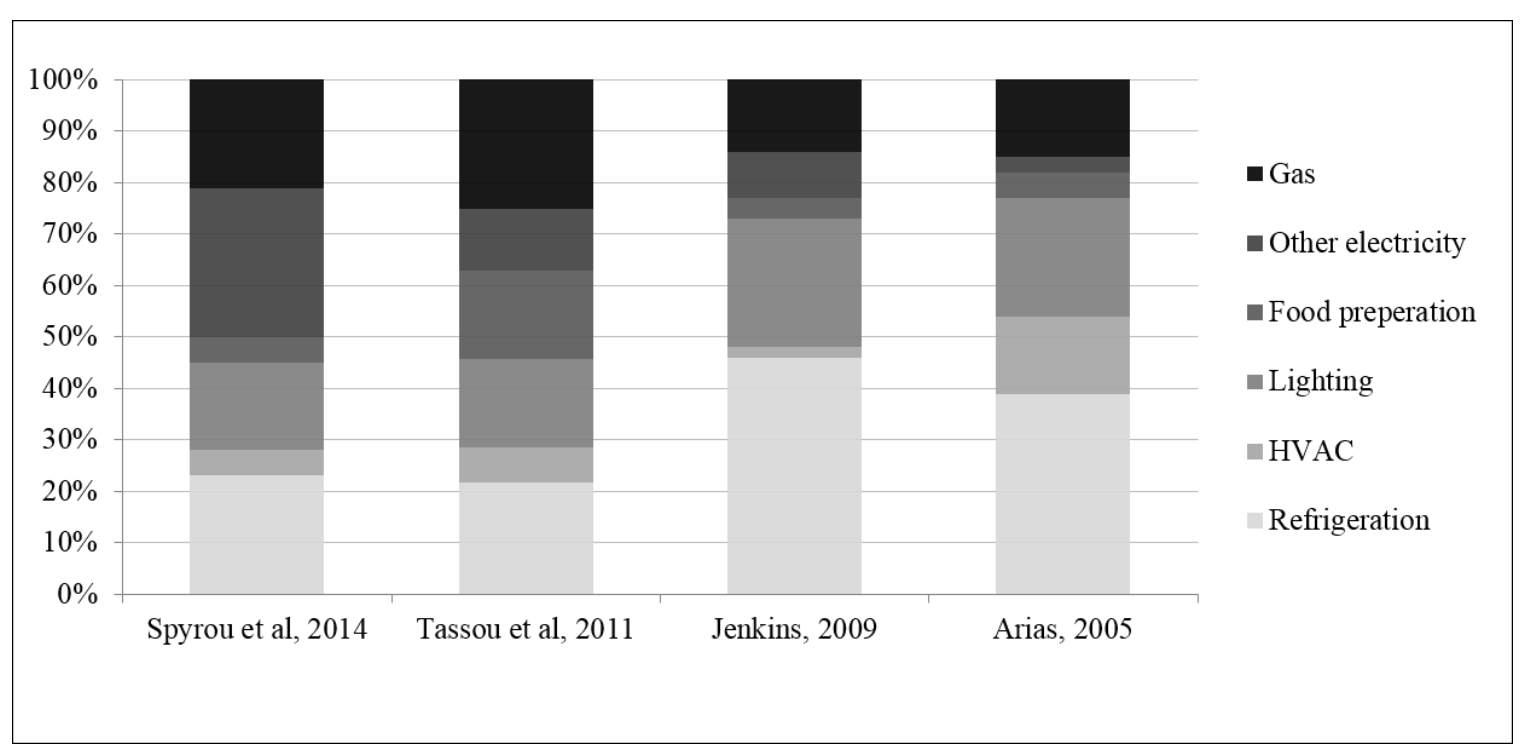

Figure 2. Proportional energy end-use in large food retail stores (Jenkins' example uses modelled data). ${ }^{1,9-11}$

Results reported by both large-scale UK research projects are similar in terms of end-use, suggesting that refrigeration accounts for approximately $25 \%$ of overall consumption. Of particular note in the published work is the modelled example provided by Jenkins; ${ }^{9}$ this follows a traditional method of simulation and includes heat gains from refrigeration equipment within the model. These modelled heat gains decrease heating demand hence the predicted HVAC and Gas end-use being significantly lower than the other UK examples; this means that both energy and associated carbon emissions are underestimated and will contribute to a perceived gap between predicted and actual performance. This is demonstrative of the difference between modelled heat rejection within the building (Jenkins example) and the reality of rejecting heat externally (Spyrou and Tassou examples).

Existing research uses advanced modelling techniques to understand localised heat transfer from SFA refrigerated displays. ${ }^{12-14}$ Cold spillage from display cases is simulated in these examples using computational fluid dynamics. The examples found in the literature either focus on refrigeration unit performance specifically ${ }^{13}$ or the impact on customer comfort rather than whole building energy performance modelling. ${ }^{12,14}$ A recent piece of work has also sought to quantify the impact of open refrigeration cases on space conditioning energy within supermarket buildings. ${ }^{15}$ This work used a supermarket DTS model coupled with a detailed HVAC systems model and can be used to complete analysis of the interactive performance of the HVAC and refrigeration systems as a whole. This approach is comprehensive but is too complex for simple early stage design and performance estimates to be produced with DTS modelling techniques used in regulatory compliance calculations.

\section{Building simulation methodology}

The aim of this work was to use calibrated DTS models to derive a unitised model input $\left(\mathrm{W} / \mathrm{m}^{2}\right)$ for the chilled SFA. Initial models include proxy refrigeration units within the main 
SFA zone. Once the models including proxy units had been calibrated, the proxy units were removed and models were then simplified to include a chilled SFA with refrigeration PHE input values to represent the heat exchanged between conditioned spaces and the refrigeration units contained within the stores; it is at this stage that a sensitivity analysis was completed to identify a suitable PHE input and results again calibrated against metered data as reiterated later in this section. All simulation models were produced using IES Virtual Environment software version 2014.2.1.0 using the bulk air movement application (Macroflo) coupled the thermal simulation engine (Apache). ${ }^{16}$

\section{Model Calibration}

A comprehensive review of calibration methods has been published elsewhere by Coakley et al. ${ }^{17}$ This review divides calibration approaches into two main categories, namely "manual" and "automated" methods. A manual approach is adopted in this work. The review goes on to define sub-categories of calibration methods. The approach used in this work is sub-categorised as a "procedural extension" and further as an "evidence-based development" approach. This differs from a basic iterative approach as, in order to increase the consistency of results, it is necessary to document and evidence model updates. ${ }^{17}$ Coakley $e a^{17}$ describe the problem of accuracy within complex building simulation as one that is "over-parameterised" and "under-validated." In this instance, this is particularly relevant to occupancy and natural ventilation (door opening schedules) as empirical data was not available for these parameters. Wherever possible model input data was obtained from the building owner/operators. Where there is no empirical source, inputs from the NCM have been used as a default. ${ }^{3}$ Inputs that rely on NCM values include occupant density ( $\mathrm{m}^{2} /$ person), hot water demand $(1 / \mathrm{s} /$ person) and internal gains from equipment in non-sales floor areas such as office space and toilets. ${ }^{3}$

The American Society for Heating, Refrigeration and Air Conditioning Engineers (ASHRAE) specify a range of error that is allowable for a model to be considered calibrated. ${ }^{18}$ These measures include the Mean Biased Error (MBE) and Cumulative Variation of Root Mean Squared Error (CVRMSE). Monthly consumption data from 2014 was provided for the case study stores used in this work; when using monthly data, a model is considered calibrated when the MBE is within 5\% and the CVRMSE is within 15\%. The MBE and CVRMSE error margins are calculated using formulae published previously. ${ }^{18 \text {, }}$

${ }^{19}$ For both measures of error, the lower the percentage error is (either positive or negative), the less each monthly total deviates from the metered values. Real weather conditions from during 2014 inevitably differed from the 'average year' simulation weather data therefore some error was expected for outputs that are weather dependant; heating gas consumption for example will differ dependent upon external conditions.

\section{Case study buildings and simulation inputs}

Both case study stores examined in this paper are relatively new and Building Information Management (BIM) models were available from the supermarket operators. Available data also included Building Regulations Part L calculation inputs and air pressurisation test results. In addition, sub-metered energy monitoring data was available for both stores which allowed them to be more accurately calibrated. The calibration of the models represented a critical element in the development of this methodology. 
The majority of input data were derived from sources provided directly by the building owner/operators, much of which was contained in the BIM models mentioned above. This included inputs for geometry, constructions, Heating, Ventilation and Air Conditioning (HVAC) systems, heating set points and schedules, cooling set points and schedules, lighting types, levels and schedules, equipment operating schedules and ventilation rates and schedules. Local simulation weather files were selected for the two stores with both models using CIBSE Test Reference Year (TRY) files for the Leeds region. Stores have been anonymised and are referred to here as 'Store A' and 'Store B.' Both buildings are in semi-urban sites, Store A has a total floor area of $6,033 \mathrm{~m}^{2}$, of which $3,752 \mathrm{~m}^{2}$ is the SFA; Store B has a total floor area of $6,138 \mathrm{~m}^{2}$ and a SFA of $4,415 \mathrm{~m}^{2}$. They are both categorised as 'Superstores.' It is noteworthy that the percentage of SFA from the whole is over $60 \%$ in both instances which is higher than the commonly accepted $50 \%$ cited earlier. Anecdotal evidence from the supermarket operators' suggests that this is due to newer stores being designed with less storage space than their older counterparts. A wider range of data is however required to confirm this formally.

Construction details are very similar in both stores. Store A was built in 2012 and Store B was built in 2014, both buildings met Building Regulation standards for the time of construction. Store A has a larger volume with an average SFA ceiling height of approximately $9 \mathrm{~m}$ as opposed to the average SFA ceiling height of $7 \mathrm{~m}$ in Store B. Store A is open 24 hours per day apart from Sunday (10am - 4pm) whereas Store B opens between $7 \mathrm{am}$ and 10pm Monday-Saturday with the same Sunday hours as Store A. Heating and cooling set points for the SFA are the same for both stores. The SFAs are heated to $19^{\circ} \mathrm{C}$ with a set-back temperature of $16^{\circ} \mathrm{C}$; the set-back temperature is active during closing hours in Store A and between 10pm and 7am in Store B. In the summer months a cooling set point of $24^{\circ} \mathrm{C}$ is used between $7 \mathrm{am}$ and $10 \mathrm{pm}$. Auxiliary ventilation rates for the SFA and other zone types were set to deliver the minimum volume of air (10 1/s/person) recommended by $\mathrm{CIBSE}^{20}$; this ventilation was however controlled using the occupancy schedule in accordance with advice from the facility managers that these rates are reduced as occupancy decreases. Equipment consumption and operating schedules for food preparation and lighting energy were also based upon actual metered data. Store A uses gas as its main heating fuel as opposed to Store B which uses electric heat pumps. A summary of model inputs are shown in Table 2.

Table 2: Summary of baseline simulation model inputs

\begin{tabular}{lcc}
\hline Parameter: & Store $\boldsymbol{A}$ & Store $\boldsymbol{B}$ \\
\hline Main wall U-value $\left(\mathrm{W} / \mathrm{m}^{2} \cdot \mathrm{K}\right)$ & 0.2700 & 0.2655 \\
\hline Roof U-value $\left(\mathrm{W} / \mathrm{m}^{2} \cdot \mathrm{K}\right)$ & 0.2500 & 0.2402 \\
\hline Ground floor $\mathrm{U}-\mathrm{value}\left(\mathrm{W} / \mathrm{m}^{2} \cdot \mathrm{K}\right)$ & 0.2318 & 0.2200 \\
\hline Infiltration rate $($ air changes per hour) & 0.250 & 0.230 \\
\hline Mechanical ventilation $(\mathrm{l} / \mathrm{s} /$ person) & 10 & 10 \\
\hline Heat source & Gas boiler & Electric heat pump \\
\hline Heat source CoP & 0.84 & 2.64 \\
\hline SFA Heating set point $\left({ }^{\circ} \mathrm{C}\right)$ & 19 & 19 \\
\hline
\end{tabular}




\begin{tabular}{lcc}
\hline SFA Heating off-schedule set-back $\left({ }^{\circ} \mathrm{C}\right)$ & 16 & 16 \\
\hline Chiller CoP & 2.1 & 1.9 \\
\hline SFA cooling set point $\left({ }^{\circ} \mathrm{C}\right)$ & 25 & 25 \\
\hline SFA main lighting gains $\left(\mathrm{W} / \mathrm{m}^{2} / 100 \mathrm{lux}\right)$ & 1.20 & 0.86 \\
\hline SFA equipment gains $\left(\mathrm{W} / \mathrm{m}^{2}\right)$ & 5.20 & 5.20 \\
\hline Occupant density $\left(\mathrm{m}^{2} / \mathrm{person}\right)$ & 8.56 & 8.56 \\
\hline Opening hours $($ Mon-Sat) & 24 hours & $07: 00-22: 00$ \\
\hline
\end{tabular}

Zone types and refrigeration units. For the sake of clarity, refrigeration cases are referred to in this work as either 'High Temperature' (HT) for chilled produce cases or 'Low Temperature' (LT) for frozen produce cases. The facility managers consulted in this work confirmed that HT and LT refrigeration are common terms used within the industry. There are also examples of this terminology being used in the academic literature ${ }^{21-24}$.

Zone types used in the models are based upon those defined in the NCM and include: circulation, storage, eating/drinking, food preparation, light plant, office space, general sales areas, toilets and general retail warehouse areas. In the baseline models using the proxy refrigeration units there are also: HT SFA units; HT storage spaces (BOH); LT SFA units; LT storage spaces (BOH). The $\mathrm{BOH}$ high and low temperature storage spaces allow for staff to walk in and have a ceiling height of $2.8 \mathrm{~m}$ and as such have an input for occupancy whereas geometry for the high and low temperature SFA proxy units was based upon dimensions taken from drawings for the internal storage sizes of the respective units.

There are a range of storage temperatures for the HT units and these represent the larger proportion of units on the SFA; an average set point of $3^{\circ} \mathrm{C}$ was used in the proxy HT spaces and a set point of $-19^{\circ} \mathrm{C}$ was used in the LT spaces based upon observed values. In the models, temperatures in these spaces are maintained at these values by separate cooling systems to the main HVAC system. An example of the proxy refrigeration unit model geometry is shown in Figure 3; the proxy units are shaded in black.

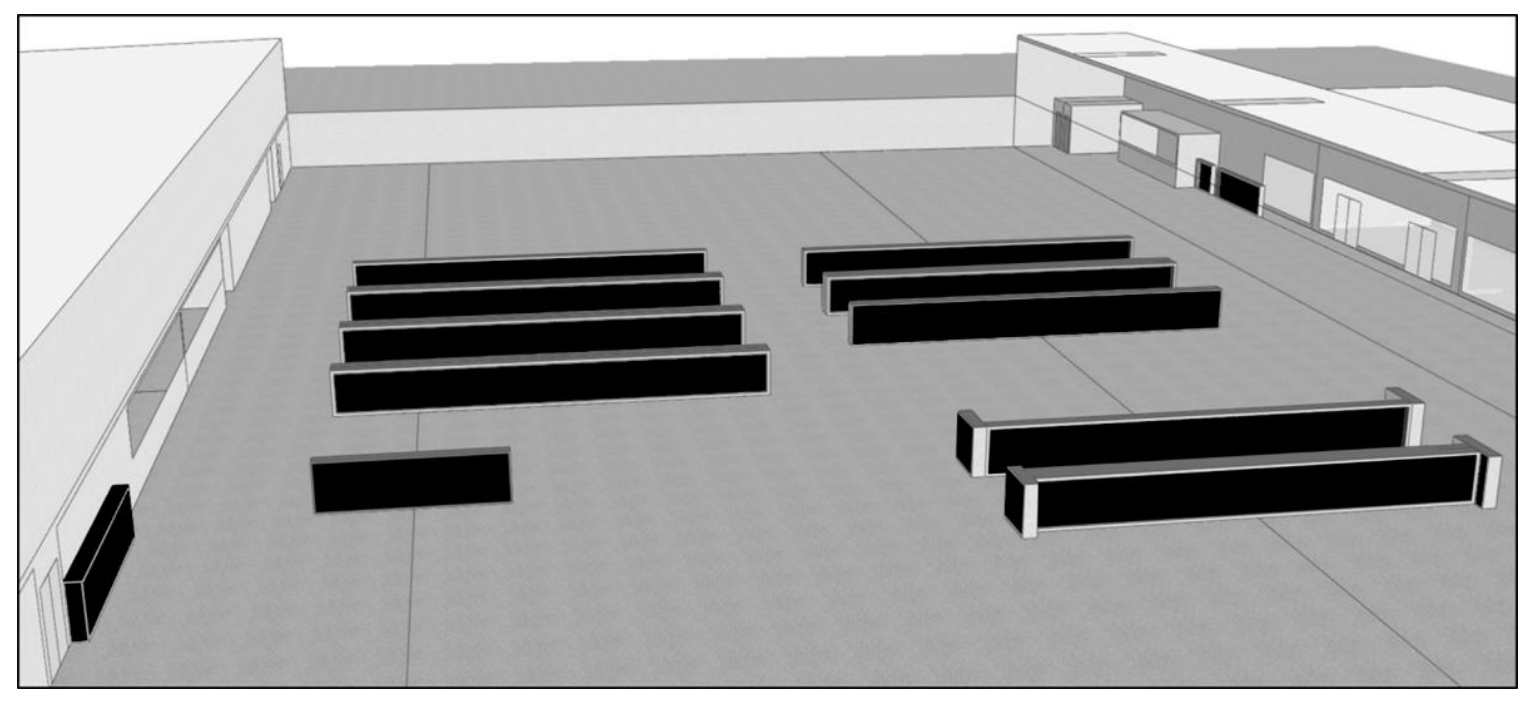

Figure 3. Proxy SFA refrigeration units in a case study Store B simulation model. 
Anecdotal advice from the facility managers confirmed that the SFA refrigeration units create a microclimate within the aisles in which they are located. Monitored data collected in both case study stores found the air temperature in shelving opposite refrigerated cabinets to be as low as $15^{\circ} \mathrm{C}$. This data is only indicative as it was not possible to carry out detailed monitoring within the operational stores. It is therefore only implicitly understood that a microclimate is produced. There is however evidence of these effects that are noted in the literature ${ }^{12-14}$.

The software used in this work does not allow for individual refrigeration units to be modelled discreetly, this is why units in the baseline models are described as a proxy. As neither the heating nor cooling systems in these models had a set peak capacity (this information could not be confirmed), it was necessary to introduce opening doors to the face of all units to mimic the microclimate conditions that are produced in the real store. The DTS models used here are nodal and the geometry of the main SFA and chilled SFA are modelled as single large zones, with air mixed evenly throughout the space. Without doors added to the units in the model, the predicted consumption was exponentially higher than in reality. This is because the heating system and proxy refrigeration systems continually counter one another in the absence of peak capacity inputs.

It is important to reiterate that the proxy refrigeration systems were used to establish a heat balance between the different physical systems operating within these buildings; they were not meant to provide a complex model of the refrigeration systems themselves. An input schedule was used to control the opening of the notional doors on the proxy units. This schedule followed the same pattern as the modelled occupancy profiles for the SFA. The factors used to control the notional door opening times equated to 2.4 minutes of an hour at their lowest and 4.2 minutes of an hour at their highest values. Empirical data for the refrigeration consumption in the actual buildings records a fluctuation in consumption that relates to opening hours, heating schedules and peak occupancy. The notional door opening schedule followed the pattern shown in Figure 8 in the results section although using the values noted above; these values were not meant to represent actual opening times but were used to limit the heat exchange between the proxy units and the SFA spaces in the model. In the sample set of stores shown in Figure 1, none of the HT display cases in the superstore and hypermarket categories had doors whilst the majority of LT units did use doors. In the two stores examined in this paper, the aisles with HT units account for $87.45 \%$ of the chilled SFA in Store A and $84.44 \%$ of the chilled SFA in Store B. In Store A, $17 \%$ of the LT units did not have doors and in Store B this proportion was $21 \%$ (these were low-height open chest freezer type units).

Simplified models and refrigeration process heat exchange. Three stages were used in the development of this methodology. The first was to create a baseline model for both stores that includes the proxy refrigeration units and to calibrate the predicted performance against consumption data from 2014. The first stage used a range of known input data as summarised in Table 2. The models were calibrated against metered data at this stage. The second stage was to replace the proxy units with a measured chilled SFA within the main SFA, effectively adding another zone type to the buildings. The convention for measuring 
the chilled SFA involved each row of refrigeration cabinets being measured from the back of the units to the centre of the aisle they faced. In the majority of instances, the units faced onto a shared aisle which simplified this exercise. This convention was used as it was more practical to take accurate measurements at this scale from the plan drawings used in this work than to measure individual units. It is also more practical to repeat for stores with limited input data.

The baseline models were created with a lower and upper area (connected by holes) for the main SFA as this allowed for separate areas of the SFA to be included and the more complex geometry of the roof and roof light constructions to be more easily modelled. The height of the lower area was set at $3 \mathrm{~m}$ and all chilled SFA areas were created at this level. The $3 \mathrm{~m}$ division also helped to simplify geometry inputs due to many of the separate zone types included in the main SFA having suspended lighting and bulkheads at this level. All separate SFA areas were connected with holes to simulate the actual store layout. Separate zones within the SFA are used to define thermal inputs only as the SFA in both stores is one large interconnected space with few partitions. An example layout for Store A is shown in Figure 4 with the chilled SFA shaded in black.

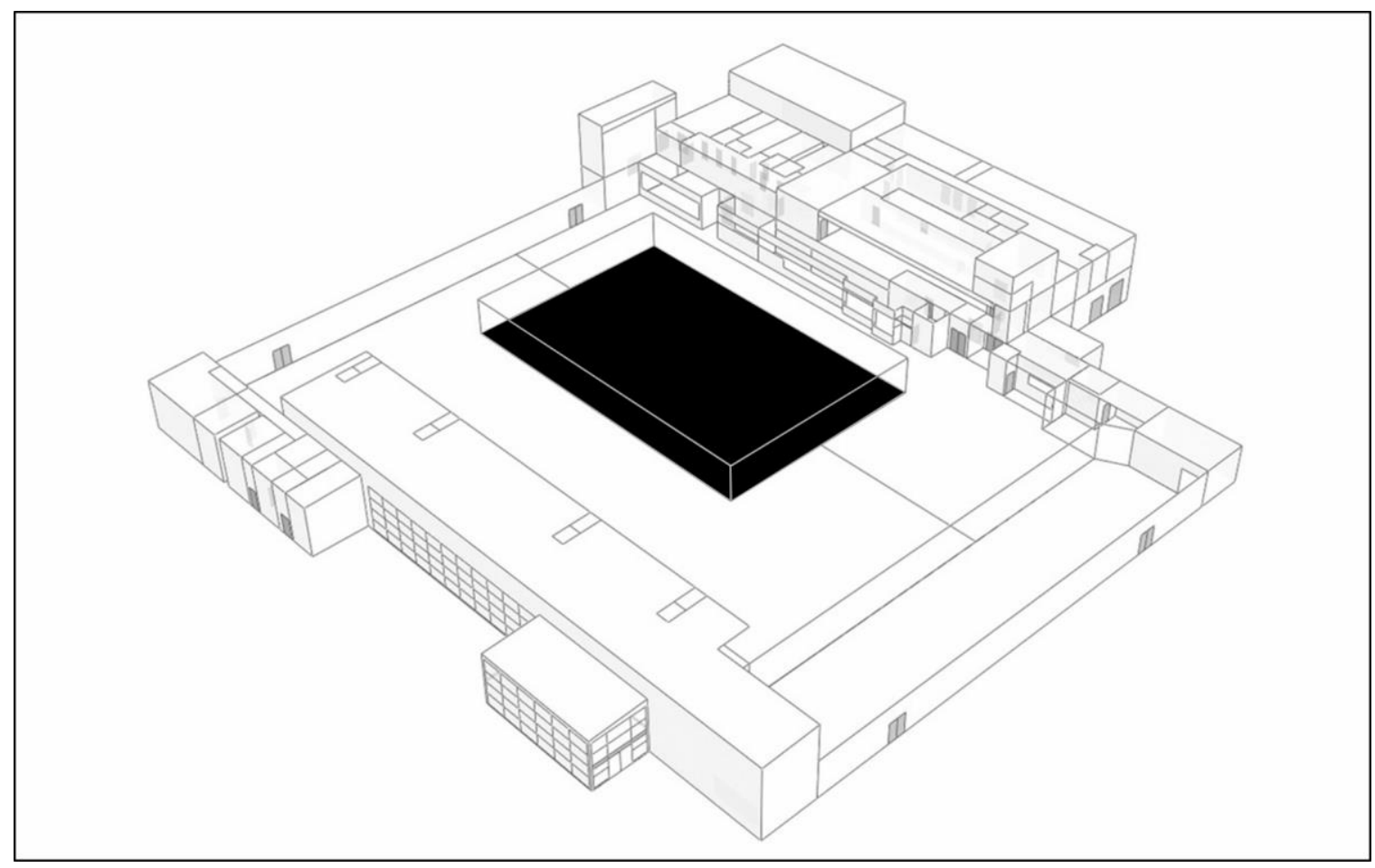

Figure 4. Case study Store A including the central chilled SFA zone.

Once the chilled SFA was added, the third and final stage of the methodology was to complete a sensitivity analysis. A range of refrigeration process heat exchange (PHE) inputs were tested to establish a $\mathrm{W} / \mathrm{m}^{2}$ figure that kept modelled performance within the allowable error range for them to be considered calibrated. As the chilled SFA replaced the proxy refrigeration units, this was the first stage in the methodology that the refrigeration PHE input was introduced. A range of inputs between $-40 \mathrm{~W} / \mathrm{m}^{2}$ and $-60 \mathrm{~W} / \mathrm{m}^{2}$ at $1 \mathrm{~W} / \mathrm{m}^{2}$ 
steps were tested in the chilled SFA zones to identify the final PHE input as described in the following results section. It is by again calibrating model outputs with metered data at this stage that a suitable PHE value could be identified as all other model inputs were unchanged from the baseline versions.

\section{Results}

\section{Baseline model including proxy refrigeration units}

In order to improve accuracy, baseline models were calibrated against sub-metered data. In the case of Store A this included sub-metered data that aligns with the categories identified in Figure 2; in addition to information provided through the store operators, this allowed for the predicted and metered performance to be cross-checked against published data (metered data provided for some of the stores in the wider data set had been found to be unrealistic and, ultimately, erroneous). There was a more limited range of end-use metered data available for Store B as sub-meters in the actual store were divided between zones rather than end-use. Figure 5 displays the MBE and CVRMSE for the Store A baseline model (including the proxy refrigeration units) measured against the metered consumption for gas (space heating and hot water), HVAC electricity (mechanical ventilation and comfort cooling), refrigeration, lighting, food preparation, small power and total energy consumption; all values fall within the allowed error for a model calibrated against monthly totals. As stated previously, the error limit for the MBE is plus or minus $5 \%$ and the error limit for the CVRMSE is plus or minus $15 \%$.

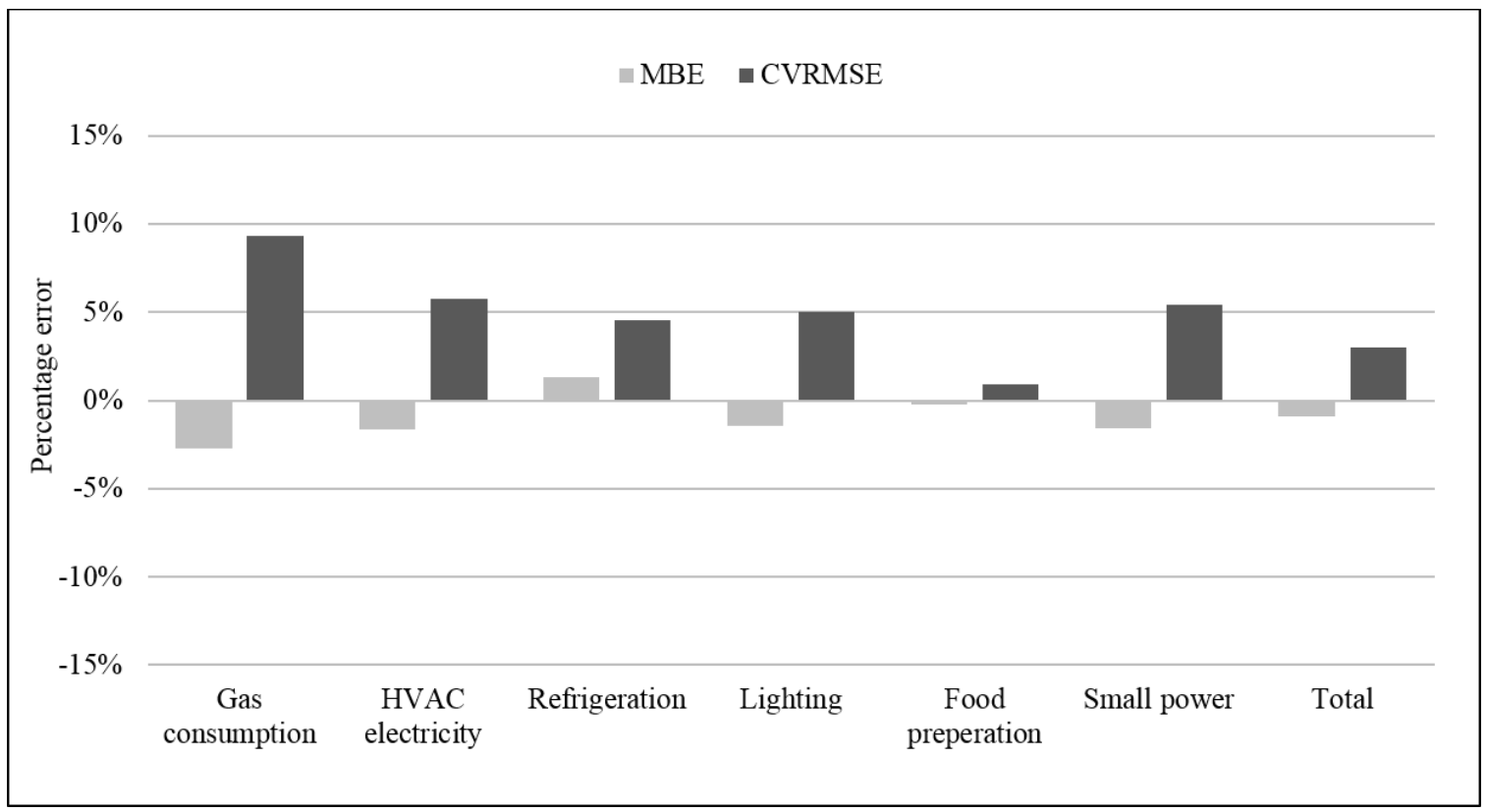

Figure 5. Model calibration error for end-use energy in baseline model of Store A.

It was expected that weather-dependent end-uses would include a margin of error as only TRY simulation weather files were available. This relates specifically to the gas and HVAC electricity consumption. Energy used for heating and cooling has a direct link to weather 
conditions due to heat exchanges associated with the building fabric and air exchanges (through ventilation and infiltration). Refrigeration energy consumption is also affected by the weather both internally and externally. Warmer internal conditions during summer months do have some impact on refrigeration energy consumption and this phenomenon is captured in the baseline version of the model. However, the externally mounted refrigeration plant efficiency is also affected by weather conditions, with the efficiency of the plant being reduced by warmer air temperatures and high humidity levels. This phenomenon is accounted for through a seasonal efficiency factor and the real, dynamic, weather variable effects of this are not reflected in the model outputs. It is therefore expected that a calibration error will be experienced for the predicted refrigeration consumption as well. The monthly consumption for all of the energy end-uses described above for Store A are shown in Figure 6.

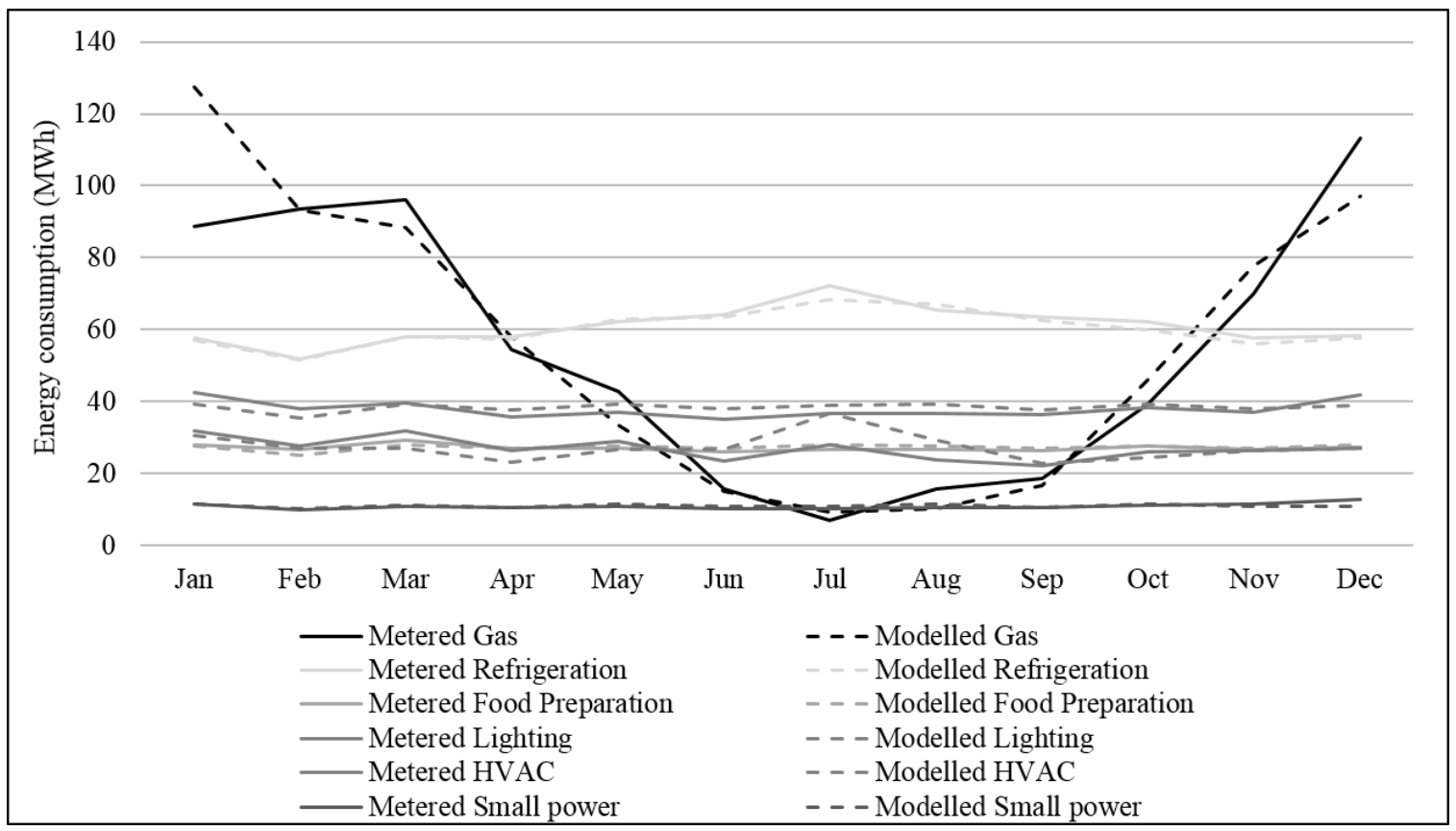

Figure 6. Metered and modelled baseline end-use energy consumption in Store A.

Proportionate end-use consumption for Store A is compared with the values recorded by Spyrou et $a l^{10}$ and Tassou et $a l^{1}$ in Table 3. It should be noted that sub-metered data for end-use consumption has some reliability issues in buildings of this nature as noncompatible loads are sometimes added to sub-meters. It is also common for "unsubmetered' electricity to account for a variety of end-uses; it has been assumed to be 'small power' in Table 3. The energy intensity of the store also aligns with the values used in the DEC assessments with $109 \mathrm{kWh} / \mathrm{m}^{2}$ and $326 \mathrm{kWh} / \mathrm{m}^{2}$ being predicted for gas and electricity respectively ${ }^{4}$. The reasons for the differences between HVAC and equipment/unsub-metered proportions are most likely related to the extent of sub-metered data that was available. It is also worth noting that the electricity fuelled over-door heaters included in the Store A model are recorded under the HVAC category.

Table 3. Proportionate energy end-use in Store A and examples from literature. 


\begin{tabular}{lccc}
\hline Energy end-use: & Store A & Spyrou et al (2014) & Tassou et al (2011) \\
\hline Gas & $25 \%$ & $21 \%$ & $25 \%$ \\
HVAC & $12 \%$ & $5 \%$ & $7 \%$ \\
Refrigeration & $27 \%$ & $23 \%$ & $22 \%$ \\
Lighting & $17 \%$ & $17 \%$ & $17 \%$ \\
Food preparation & $12 \%$ & $5 \%$ & $17 \%$ \\
Equipment/unsub-metered & $7 \%$ & $29 \%$ & $12 \%$ \\
\hline
\end{tabular}

A smaller range of sub-metered data was available for Store B. This restricted comparison of model outputs to the metered HVAC electricity, Refrigeration and combined values for equipment (small power) and lighting consumption. Figure 7 displays the MBE and CVRMSE for the Store B baseline model (including the proxy refrigeration units). It is important to note that in both models at this stage of calibration, the refrigeration consumption is only similar to the metered data as the chiller system includes a coefficient of performance value; in the next stage of calibration the proxy units (and dedicated chiller systems) are removed and the simplified input cannot be used to predict refrigeration consumption without post-processing the model outputs. Predicting refrigeration consumption is not however the focus of this work as noted in the discussion section.

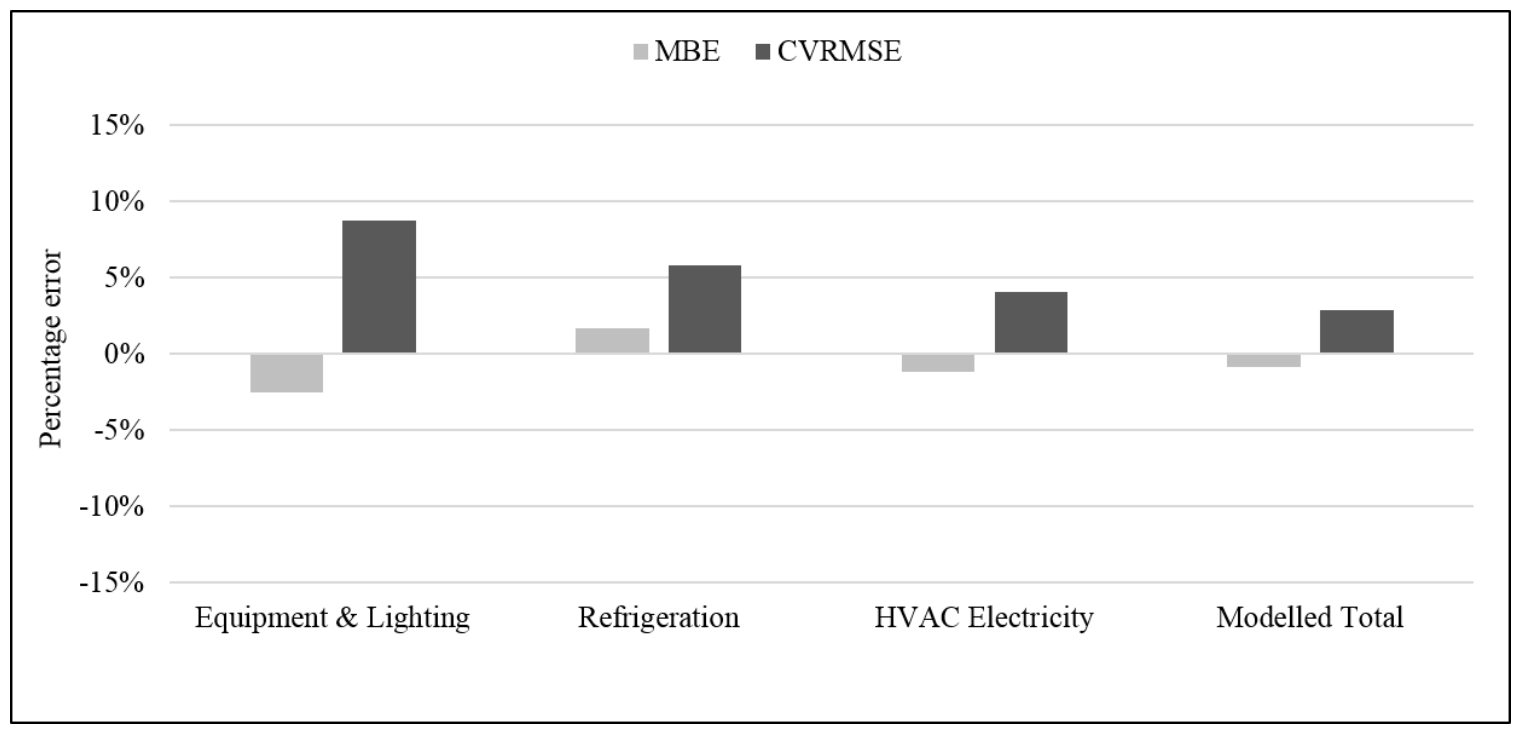

Figure 7. Model calibration error for end-use energy in Store B.

\section{Refrigeration process gains and sensitivity}

Published literature provides two calculated estimates for the refrigeration PHE driven contribution to supermarket heating loads. A publication from 1999 estimates this as approximately $34 \%$ for the total store ${ }^{21}$ and a more recent study (2014) estimates this as approximately $43 \%$ for the $\mathrm{SFA}^{2}$. In the example provided by Hill et al ${ }^{2}$ it is only the SFA energy consumption that is compared with metered data from a case study building. In the case study examples presented here, energy consumption from the total store has been used 
to calibrate baseline models and refrigeration PHE accounts for $36.17 \%$ of the total heating load in the Store A baseline model and $39.65 \%$ in the Store B baseline model. It therefore includes energy consumed for space conditioning in storage areas which interact with refrigeration heat exchange from chilled storage areas. However, these heat exchanges are much lower than those driven by the refrigeration units in the SFA. The heating loads in the storage and $\mathrm{BOH}$ zones account for a relatively small proportion of the overall conditioning energy consumption when compared with the SFA; it is important to note however that this is based upon results from the calibrated models.

As mentioned previously, the PHE driven by refrigeration is not necessarily constant. To allow for the fluctuations in the PHE caused by door openings for the LT units and additional customer use of HT units during peak occupancy, a control profile was used as illustrated in Figure 8. The schedule controls what proportion of the PHE value is included in the model. A reduced version of this is used for Sunday and holiday opening hours which is maintained at 0.9 until 10:00, has the same profile between 10:00 and 16:00 and then drops back down to 0.9 for the rest of the day.

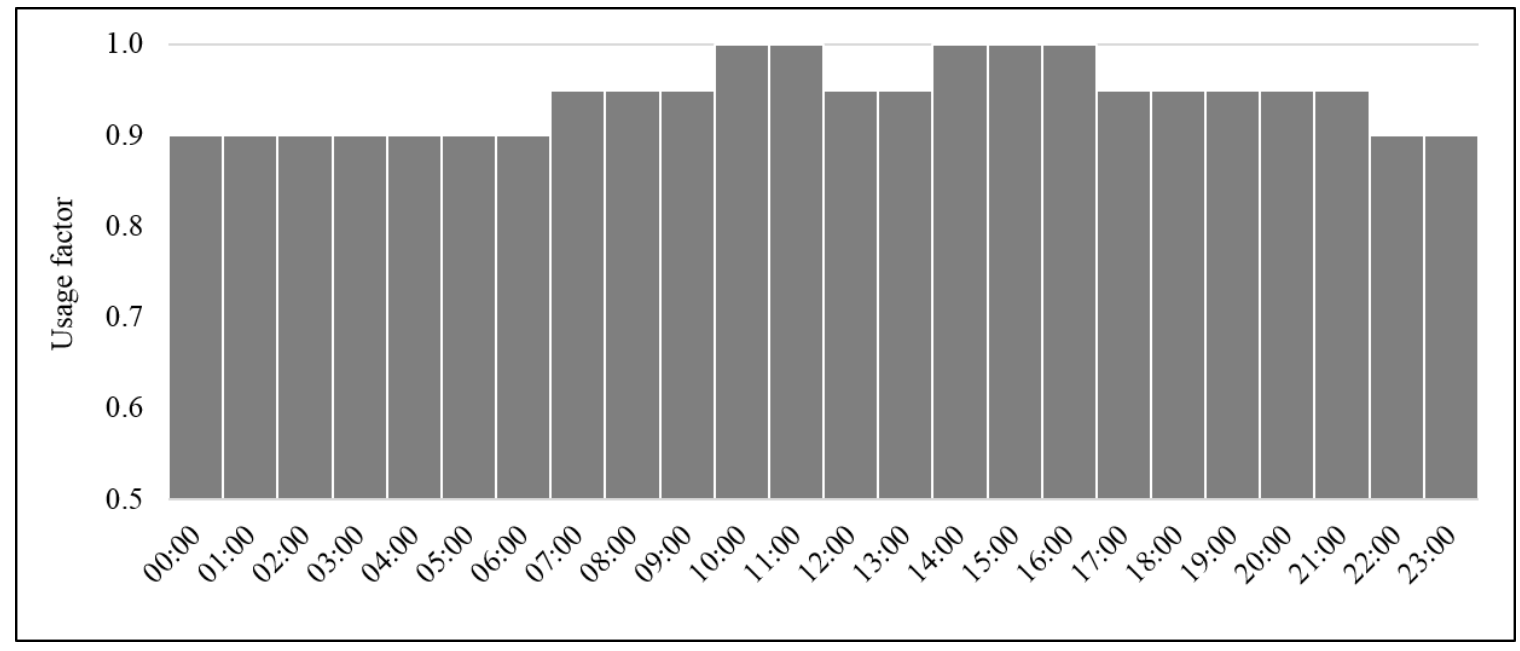

Figure 8. Control schedule for refrigeration PHE input Monday to Saturday.

The primary aim of introducing a PHE for refrigeration is to simplify the model and identify a value that can be used in design stage and regulatory compliance thermal models. Including refrigeration driven heat exchange in the model can allow for the fabric and HVAC performance to be optimised by using a more realistic representation of the heat exchanges contained within the actual building as described by Hill et al. ${ }^{25}$ It is therefore important that the space conditioning energy consumption in the simplified models remains within the allowable limits for calibration. As noted earlier, the size of the chilled SFA is not necessarily proportionate to the size of the total SFA. For this reason a single process gain value could not be calculated for the SFA alone. The refrigeration PHE value needs to be applied to a specific chilled SFA zone that forms part of the total SFA in any given supermarket DTS model. 
The first stage of introducing the PHE to the model was to test the sensitivity of the simplified model to a range of input values. A range of inputs between $-40 \mathrm{~W} / \mathrm{m}^{2}$ and -60 $\mathrm{W} / \mathrm{m}^{2}$ at $1 \mathrm{~W} / \mathrm{m}^{2}$ steps were tested in the chilled SFA zones. The results of this exercise for Store A are presented in Figures 9 and 10; Figure 9 illustrates the monthly calibration errors for gas consumption and Figure 10 illustrates the same errors for HVAC electricity consumption. For Store A, both of these energy end-uses relate to the space conditioning. The purpose of this exercise across the two stores was to identify a generic refrigeration PHE value. It was therefore necessary to select the value that resulted in least error for both stores. Figure 11 illustrates the calibration errors for Store B. In the case of Store B, the heating and cooling space conditioning consumption are combined as sub-metered energy consumption was only available for HVAC electricity as a whole (this store uses electricity to provide both heating and cooling).

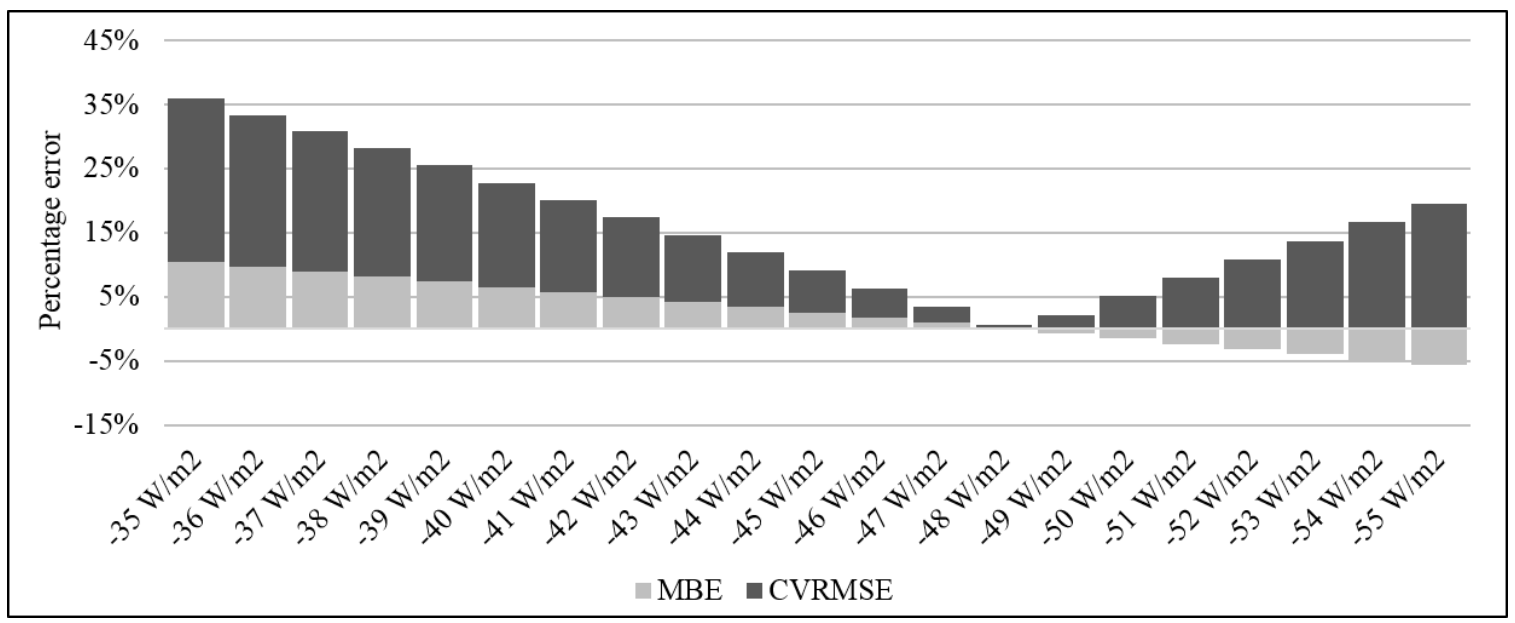

Figure 9. MBE and CVRMSE error for gas consumption in thermal models of Store A using a range of refrigeration PHE inputs.

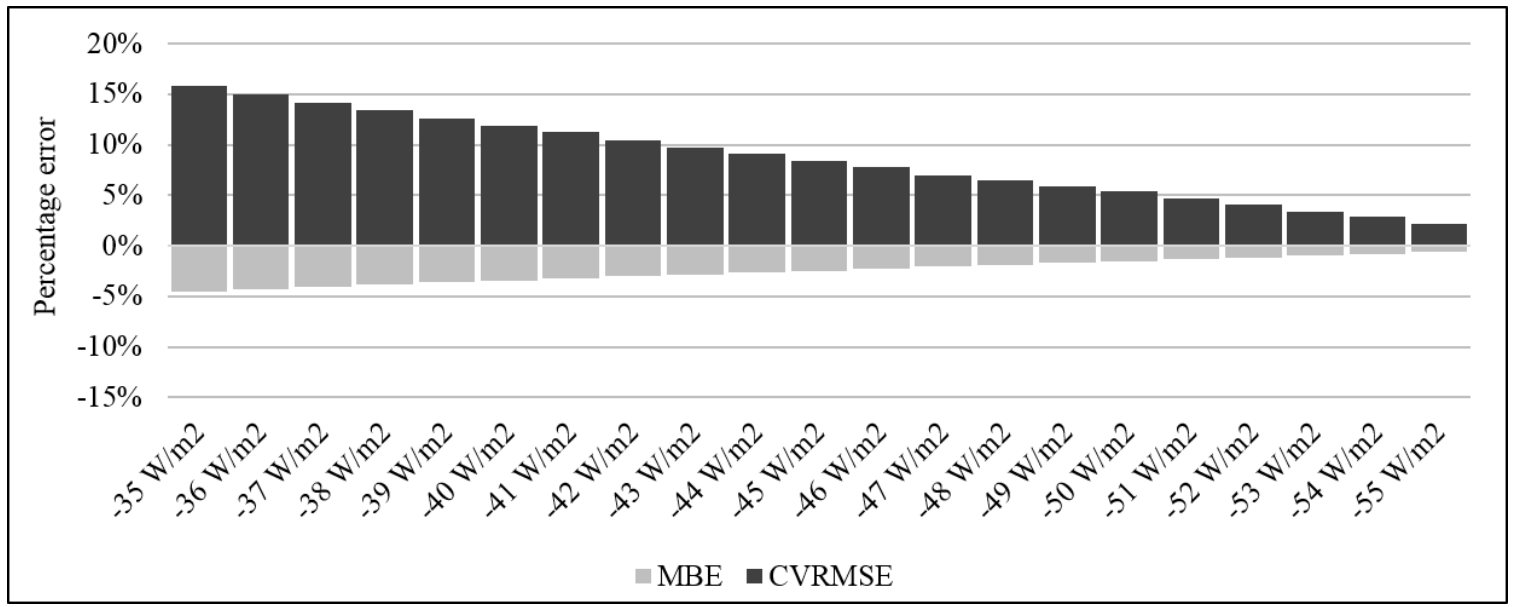

Figure 10. MBE and CVRMSE error for HVAC electricity in thermal models of Store A using a range of refrigeration PHE inputs. 


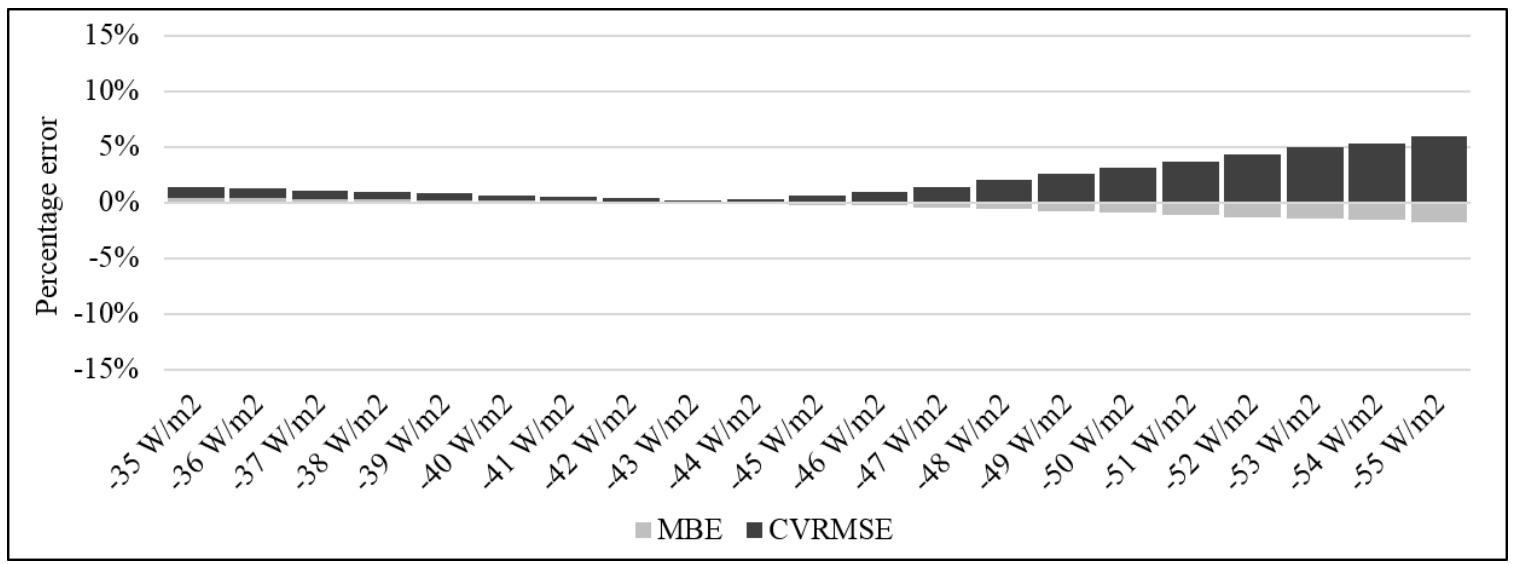

Figure 11. MBE and CVRMSE error for HVAC electricity in thermal models of Store B using a range of refrigeration PHE inputs.

The optimal input for the two stores differs slightly. The optimal refrigeration PHE value for Store A is $-48 \mathrm{~W} / \mathrm{m}^{2}$ which results in a $0.18 \% \mathrm{MBE}$ and a $0.61 \%$ CVRMSE. Within the range tested, the lowest errors for the Store A HVAC electricity are $0.63 \%$ for the MBE and $2.18 \%$ for the CVRMSE. For Store B the optimal refrigeration PHE for the modelled HVAC electricity consumption is $-43 \mathrm{~W} / \mathrm{m}^{2}$ which results in an MBE of $0.07 \%$ and a CVRMSE of $0.16 \%$. Based upon the two case study models, the refrigeration PHE input that is the best fit for both stores is $-45 \mathrm{~W} / \mathrm{m}^{2}$. The MBE and CVRMSE errors for both stores when using the $-45 \mathrm{~W} / \mathrm{m}^{2} \mathrm{PHE}$ are visualised in Figure 12. All errors remain within the respective thresholds for calibration.

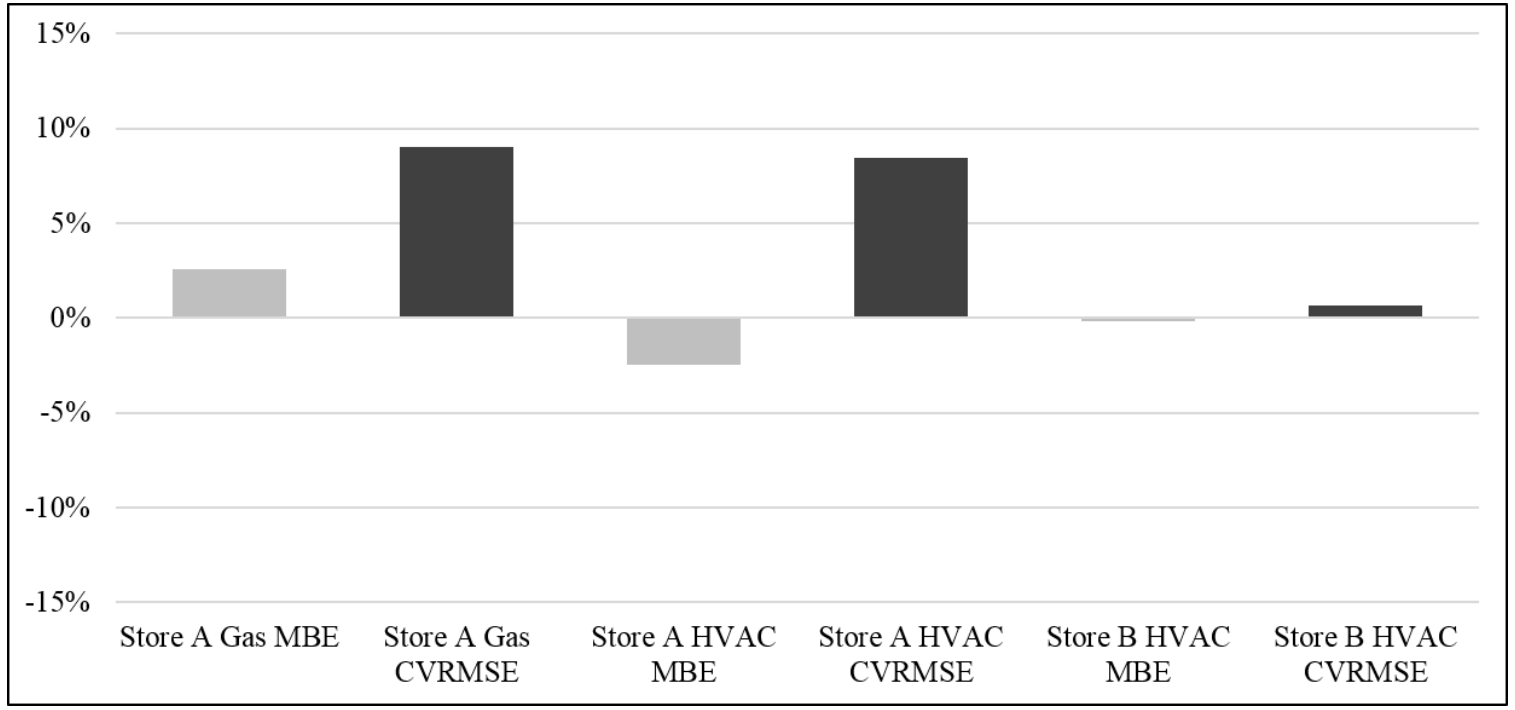

Figure 12. Calibration errors using $-45 \mathrm{~W} / \mathrm{m}^{2}$ refrigeration PHE modelling input.

\section{Discussion}

It is recognised that supermarket thermal models for early stage design and building regulations compliance typically assume an incidental heat gain in chilled SFAs, while in 
reality this heat is rejected externally meaning that refrigeration PHE will increase heating demand. In order to establish suitable thermal model inputs for the refrigeration PHE associated with the supermarket operations, a pair of models have been created and calibrated against metered data to help establish the extent of heat exchange between the conditioned internal environment and the refrigerated display units contained within them. Proxies for the refrigeration units were used in the baseline models to establish the extent of heat exchange. Wherever possible, empirical data was used to refine the model inputs. The proxy refrigeration units were replaced by a chilled SFA zone which was calculated using a simple protocol that is described in the main body of this paper. A sensitivity analysis was then carried out that identified a process gain input of $-45 \mathrm{~W} / \mathrm{m}^{2}$ that can be used to model the PHE driven by the SFA refrigeration units. It should be noted that this PHE input does not account for the proportion of units that use doors. Although the observed number of display cases with doors was very low in the two case study buildings, the effect of these has not been quantified in this work. The impact of display case doors on this type of simplified model input requires further investigation.

There are other limitations to this work which are mainly related to uncertainty in a small selection of the model inputs. Primarily, the occupancy data for the case study stores was not available as it was deemed commercially sensitive. This meant that occupant density and schedules were based upon those used in the NCM database. ${ }^{3}$ Uncertainty associated with this input was mitigated partially by tailoring the occupancy schedules to the opening hours of the respective stores. The schedule controlling auxiliary ventilation was also associated with the occupancy patterns and delivered volume of fresh air was based on industry standards for this type of building. ${ }^{20}$ It should also be noted that these results are based upon a limited sample set; further case study analysis is required to more widely validate the PHE input.

Previous work published by Hill et al. identified the need to establish thermal modelling inputs for this type of PHE but also advised that these should be divided between HT and LT refrigeration. ${ }^{2}$ Further work will be required to disaggregate the refrigeration PHE input between the HT and LT refrigeration found in modern supermarkets. In the wider data set of 40 stores that the case study buildings were selected from, there are 13 superstores; the median percentage of LT as a proportion of the total chilled SFA is $19.51 \%$; 12 of the stores have proportionate LT areas within $2.2 \%$ of this median value, the one outlier is within $5.1 \%$. This suggests that it is reasonable to combine the HT and LT PHE into a single input for this type of thermal modelling for this store type. The other store types in the sample set are supermarkets (13) and hypermarkets (14). The median value for supermarkets is $18.79 \%$ with 10 of these stores being within $2 \%$; the median value for hypermarkets is $18.95 \%$ with 10 of these stores being within $1.5 \%$. Based upon this relatively small sample, these statistics suggest that a combined PHE input value may be less suitable for these store types although a wider study would be required to clarify this. A separate specific value for HT and LT refrigeration would provide a more flexible solution. Creating a separate input for LT SFA units could be further complicated by the different heat exchanges driven by units with and without doors. 


\section{Conclusion}

A refrigeration PHE value has been established in this paper that can be used in dynamic thermal simulation models to account for the PHE driven by in-store refrigeration in supermarkets. This allows for the heat balance in these buildings to be more realistically modelled at early design stage and in regulatory compliance DTS calculations and can help designers and owner/operators of these buildings to produce more realistic estimates of whole building performance. When validated against a wider sample set, the PHE identified in this work can ultimately be developed into a data input that can be used for regulatory compliance calculations. Although this study is based upon two large food retail stores in the UK, the heat exchanges investigated here also have the potential to improve the early stage whole building design of these facilities internationally. The identified PHE can be used in store energy models of a similar scale in other countries, assuming that they include a comparable range of HT and LT units. The data inputs identified in this work can help improve the whole building thermal performance analysis of supermarkets across both developing and mature economies.

\section{Funding}

This work was funded by Innovate UK as part of their Future Energy Management of Buildings programme.

\section{Acknowledgements}

The authors wish to acknowledge the support of Cybula Ltd in the development of this work.

\section{References}

1. Tassou SA, Ge Y, Hadawey A and Marriott D. Energy consumption and conservation in food retailing. Applied Thermal Engineering. 2011; 31: 147-56.

2. Hill F, Edwards R and Levermore G. Influence of display cabinet cooling on performance of supermarket buildings. Building Services Engineering Research and Technology. 2014; 35: 170-81.

3. HM Government. National Calculation Methodology (NCM) modelling guide (for building other than dwellings in England and Wales). London: BRE Ltd, 2013.

4. CIBSE. TM46: Energy Benchmarks. London2008.

5. ASHRAE. Advanced energy design guide for medium to large box retail buildings. Atlanta2011.

6. CIBSE. TM47: Operational ratings and display energy certificates. London2009.

7. The Institute of Grocery Distribution. UK Grocery Retailing. 2015.

8. Braun MR, Altan $\mathrm{H}$ and Beck SBM. Using regression analysis to predict the future energy consumption of a supermarket in the UK. Applied Energy. 2014; 130: 305-13.

9. Jenkins DP. Using dynamic simulation to quantify the effect of carbon-saving measures for a UK supermarket. Journal of Building Performance Simulation. 2008; 1: 275-88.

10. Spyrou MS, Shanks K, Cook MJ, Pitcher J and Lee R. An empirical study of electricity and gas demand drivers in large food retail buildings of a national organisation. Energy and Buildings. 2014; 68: 172-82. 
11. Arias J. Energy usage in supermarkets - modelling and field measurements. . Division of Applied Thermodynamics and Refrigeration, Department of Energy Technology. Royal Institute Technology, 2005.

12. Foster AM and Quarini GL. Using advanced modelling techniques to reduce the cold spillage from retail display cabinets into supermarket stores to maintain customer comfort. Proceedings of the Institution of Mechanical Engineers, Part E: Journal of Process Mechanical Engineering. 2001; 215: 29-38.

13. Navaz HK, Faramarzi R, Gharib M, Dabiri D and Modarress D. The application of advanced methods in analyzing the performance of the air curtain in a refrigerated display case. Journal of Fluids Engineering, Transactions of the ASME. 2002; 124: 756-64.

14. Tassou SA and Xiang W. Interactions between the environment and open refrigerated display cabinets in retail food stores - Design approaches to reduce shopper discomfort. ASHRAE Transactions. 2003, p. 299-303.

15. Witt HT, S. Lomas, K. Liddiard, L. Simulation of energy use in Uk supermarkets using EnergyPlus. 14th Conference of International Building Performance Simulation Association. Hyderabad, India: IBPSA, 2015, p. 1095-102.

16. IES. Virtual Environment. 2014.2.1.0 ed. 2014.

17. Coakley D, Raftery P and Keane M. A review of methods to match building energy simulation models to measured data. Renewable and Sustainable Energy Reviews. 2014; 37: 123-41.

18. ASHRAE. ASHRAE Guideline 14-2002, Measurement of Energy and Demand Savings. Atlanta2002.

19. Raftery P, Keane M and Costa A. Calibrating whole building energy models: Detailed case study using hourly measured data. Energy and Buildings. 2011; 43: 3666-79. 20. CIBSE. Guide A: Environmental Design. London2006.

21. Maidment GG, Zhao X, Riffat SB and Prosser G. Application of combined heatand-power and absorption cooling in a supermarket. Applied Energy. 1999; 63: 169-90.

22. Maidment GG and Tozer RM. Combined cooling heat and power in supermarkets. Applied Thermal Engineering. 2002; 22: 653-65.

23. Sugiartha N, Tassou SA, Chaer I and Marriott D. Trigeneration in food retail: An energetic, economic and environmental evaluation for a supermarket application. Applied Thermal Engineering. 2009; 29: 2624-32.

24. Ge YT and Tassou SA. Performance evaluation and optimal design of supermarket refrigeration systems with supermarket model "SuperSim", Part I: Model description and validation. International Journal of Refrigeration. 2011; 34: 527-39.

25. Hill F, Watkins R and Edwards R. Developing figures for 'gain' in relation to refrigerated cabinets in a supermarket building. Building Services Engineering Research and Technology. 2014; 35: 465-74. 